\section{Commentary: Morning, afternoon, and evening}

\author{
J. W. Awori Hayanga, MD, MPH, and \\ Vinay Badhwar, MD
}

"The afternoon knows what the morning never suspected." When poet Robert Frost wrote this statement about wisdom and mentorship, it is unlikely that he imagined its application to cardiothoracic surgery. In many ways, the agerelated core principles of wisdom and experience are as essential to the growth of our early-career colleagues as they are to the mentorship of our residents and fellows. American Association for Thoracic Surgery Past President Marc Moon ${ }^{1}$ notes these truths, then interprets how these might evolve with a surgeon's career in operative cardiac surgery.

In adjudicating aging surgeons, it is difficult to overstate the role and influence of the team within the system. As such, one would endorse that surgery is a team sport and that any subtle individual decline of a surgeon may be mitigated by the strengths and protections of the team within an infrastructure of excellence that maintains accountability, patient safety, and overall quality. These processes, common in larger quaternary programs, include a close working environment of multiple surgical partners with access to advanced diagnostic testing, skilled interventionalists, experienced cardiac anesthesiologists, and intensivist-driven postoperative care. Such programmatic mechanisms decrease the incidence of failure to rescue. As such, although complication rates tend to be similar across tertiles of

From the Department of Cardiovascular and Thoracic Surgery, West Virginia University, Morgantown, WVa.

Disclosures: The authors reported no conflicts of interest.

The Journal policy requires editors and reviewers to disclose conflicts of interest and to decline handling or reviewing manuscripts for which they may have a conflict of interest. The editors and reviewers of this article have no conflicts of interest.

Received for publication Dec 5, 2021; revisions received Dec 5, 2021; accepted for publication Dec 6, 2021; available ahead of print Dec 9, 2021.

Address for reprints: J. W. Awori Hayanga, MD, MPH, Department of Cardiovascular and Thoracic Surgery, West Virginia University, 1 Medical Center Dr, Morgantown, WV 26506 (E-mail: jeremiah.hayanga@wvumedicine.org).

J Thorac Cardiovasc Surg 2022;164:1028-9

$0022-5223 / \$ 36.00$

Copyright (c) 2021 by The American Association for Thoracic Surgery

https://doi.org/10.1016/j.jtcvs.2021.12.012

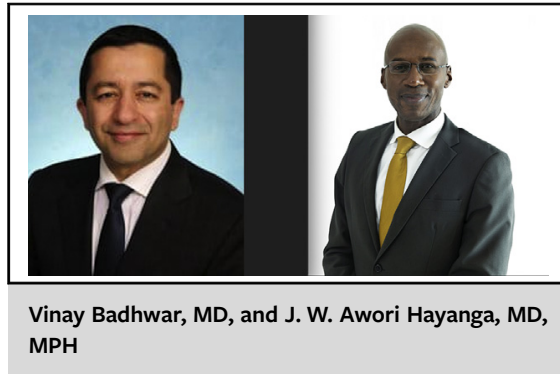

CENTRAL MESSAGE

Every career in cardiothoracic surgery has a morning, afternoon, and an evening.

volume, individual response to complications varies by institution, and with it, so too does survival. ${ }^{2}$ Trauma systems have proven that the system is more important than individual surgeons in determining the outcome. ${ }^{3}$ As an example of system-based care, the Efficacy and Economic Assessment of Conventional Ventilatory Support versus Extracorporeal Membrane Oxygenation for Severe Adult Respiratory Failure trial confirmed that transfer to an extracorporeal membrane oxygenationcapable center had a more significant correlation with improved survival than the use of extracorporeal support itself.

Moon ${ }^{1}$ explores the evolution and eventual diminution of operative skill with age and alludes to its nonlinear relationship in this regard. To objectively evaluate outcomes, however, one must also consider that an older, experienced surgeon may serve as an operative mentor and permit transference of skills with the provision of a safety net through a "second, younger cognitive presence" 1 to accompany the more seasoned hands in an operating room. The balance suggests a win-win situation in which surgeons of different ages and skills can play a role in maintaining the safety standards and quality in the context of reoperative cardiac surgery. Admittedly, such a model confounds the interpretation of the results as any untoward outcomes would be shared and not deemed the responsibility of 1 individual versus the other. Comparisons would be further impaired by inherent selection bias because cases in which a dual presence was necessary may be the ones with higher complexity and more prone to adverse outcomes regardless of operator. Once again, the system is likely to be the common denominator 
in balancing out any operator variations. We are a specialty that values the wisdom and experience of senior surgeons, yet one that exerts little jurisdiction over a specific age of retirement. For some senior colleagues, technical proficiency and quality may indeed be preserved and the choice of retirement may be a personal one. For some, it may not. At a time when a growing number of senior surgeons are actively practicing, Moon's ${ }^{1}$ contribution helps objectively define the evening of a career in cardiothoracic surgery.

\section{References}

1. Moon M. Early- and late-career surgeon deficiencies in complex cases. J Thorac Cardiovasc Surg. 2022;164:1023-5.

2. Ghaferi AA, Birkmeyer JD, Dimick JB. Hospital volume and failure to rescue with high-risk surgery. Med Care. 2011;49:1076-81.

3. Haut ER, Chang DC, Hayanga AJ, Efron DT, Haider AH, Cornwell EE III. Surgeon- and system-based influences on trauma mortality. Arch Surg. 2009;144: 759-64.

4. Peek GJ, Mugford M, Tiruvoipati R, Wilson A, Allen E, Thalanany MM, et al; CESAR trial collaboration. Efficacy and economic assessment of conventional ventilatory support versus extracorporeal membrane oxygenation for severe adult respiratory failure (CESAR): a multicentre randomized controlled trial. Lancet. 2009;374:1351-63. 